\title{
BRCA2 Syndrome
}

National Cancer Institute

\section{Source}

National Cancer Institute. BRCA2 Syndrome. NCI Thesaurus. Code C36101.

An autosomal dominant inherited syndrome caused by mutations in the BRCA2 gene.

Patients are at high risk of developing female and male breast cancer, ovarian cancer, and other cancers including prostatic cancer, pancreatic cancer, gastric cancer, and melanoma. 